\title{
Assessment of Radiological Dose around a 3-MW TRIGA Mark-II Research Reactor
}

\author{
A. F. M. M. Rahman ${ }^{1}$, M. Shamsuzzaman ${ }^{1}$, M. S. Rahman ${ }^{1}$, K. Uddin ${ }^{1}$, \\ S. Yeasmin ${ }^{2}$, H. M. Nazmul Haque ${ }^{3}$, M. M. Akramuzzaman ${ }^{3}$, \\ Shyamal Ranjan Chakraborty ${ }^{4, *}$ \\ ${ }^{1}$ Health Physics and Radioactive Waste Management Unit, Institute of Nuclear Science and \\ Technology, AERE, Savar, Dhaka - 1349, Bangladesh \\ ${ }^{2}$ Health Physics Division, Atomic Energy Centre, Ramna, Dhaka - 1000, Bangladesh \\ ${ }^{3}$ Department of Physics, Jahangirnagar University, Savar, Dhaka - 1342, Bangladesh \\ ${ }^{4}$ Department of Physics, University of Chittagong, Chittagong - 4331, Bangladesh \\ *E-mail address: shyamal_ranjan@yahoo.co.uk
}

\begin{abstract}
A hypothetical accidental case of a 3-MW TRIGA Mark-II research reactor has been assumed to assess the radiological consequences due to the deposition of ${ }^{137} \mathrm{Cs}$ and ${ }^{90} \mathrm{Sr}$ on ground, vegetation, milk and meat. The air concentrations in sixteen cardinal directions have been estimated where the maximum concentration has been found to be at $110 \mathrm{~m}$ distance from the core of the reactor for all the directions. Calculated maximum doses of ${ }^{137} \mathrm{Cs},{ }^{90} \mathrm{Sr}$ and both ${ }^{137} \mathrm{Cs}$ and ${ }^{90} \mathrm{Sr}$ have been found to be within the ranges of $0.005-0.014 \mu \mathrm{Sv} \mathrm{hr} r^{-1}, 0.013-0.036 \mu \mathrm{Sv} \mathrm{hr}^{-1}$ and $0.018-0.05 \mu \mathrm{Sv} \mathrm{hr}{ }^{-1}$, respectively for all the directions, which are below the measured background dose limit $0.25 \mu \mathrm{Sv} \mathrm{hr}^{-1}$ and also within the IAEA acceptable dose rate limit of $0.5 \mu \mathrm{Sv} \mathrm{hr}^{-1}$. The calculated low doses due to the aforementioned radionuclides can be considered negligible with regard to the radiation hazards. The relationship between total effective dose rate for various pathways (i.e. immersion, inhalation, ground deposition, and ingestion of contaminated vegetation, milk, meat) and air concentration in all the directions has been established. Obtained relation reveals that the total effective dose rate is directly proportional to the air concentration, and the overall proportionality constants for ${ }^{137} \mathrm{Cs}$ and ${ }^{90} \mathrm{Sr}$ radionuclides have been obtained as 0.57 and 0.28 , respectively. This study might provide information on the radiological safety required for the radiation protection purposes of the people living in the vicinity of the reactor site.
\end{abstract}

Keywords: source term; release rate; TRIGA Mark-II reactor; dispersion, ingestion and deposition of radionuclide; Gaussian plume model; dose calculations

\section{INTRODUCTION}

A 3-MW TRIGA Mark-II research reactor, which can be described as the most widely used non-power nuclear reactor in the world, was commissioned at the Atomic Energy Research Establishment, Savar, Dhaka, Bangladesh in 1986 and nowadays is being used in activities such as basic nuclear research, production of radioisotopes and their applications to agriculture, industry and medicine, neutron radiography, materials testing, and so on. Among 
the numerous radionuclides released as the fission products during reactor routine operation and/or accidental cases; ${ }^{137} \mathrm{Cs},{ }^{90} \mathrm{Sr},{ }^{85} \mathrm{Kr}$ and ${ }^{131} \mathrm{I}$ are the most concerned ones due to their high radiation hazards. There are many reasons for the accident but the principal ones are the simple human error and the failure of a rather minor valve in the reactor. Moreover, accident could happen due to the failure of cooling system, fuel damage, loss of coolant, high pressure in the reactor vessel, core melting, and so on. Regardless the pathways of emission, the escaped fission products initially housed in the reactor hall and subsequently disperse in the surrounding environment through stack. The released radionuclides makes radiological doses to reactor personnel as well as to the surrounding living beings through two principal ways: external dose due to immersion in the radionuclides in the exhaust air plume and also activity deposited on the ground, and internal dose caused by radionuclides inhaled with the air and also consumption of contaminated food.

Radionuclides dispersed in the atmosphere are deposited on ground and reach to human body via food chain [1]. Of all the radionuclides released from a research reactor, ${ }^{137} \mathrm{Cs}$ and ${ }^{90} \mathrm{Sr}$ are the dominant long-lived fission products due to their high mobility in the soil-plant system, a long term bioavailability and high transfer rates into human food that results in long-term internal as well as external radiation exposures to the human [2]. The considered radionuclides amass in the blood plasma and affect the blood stem cells. This causes immune abnormality to blood cell and damage in DNA [3]. Large amount of releases of these radionuclides in the environment affect agro-ecosystems and food production, and consequently accumulate to soil-plant system potentially for many years.

For radiological safety analysis of a research reactor, a hypothetical accident is generally assumed which results in the release of some portion of the inventory of radioactive materials from the fuel to the containment/reactor building. There are many computational models developed for assessing radiological doses depending on site-specific data [4]. Different assumptions and methodologies have been used in these models. Recently, IAEA published a generic methodology for use in assessing the radiological dose due to the releases of radioactive materials in the environment $[5,6]$. In this work, radiological dose assessment for 16 cardinal directions due to the release of ${ }^{90} \mathrm{Sr}$ and ${ }^{137} \mathrm{Cs}$ from a 3-MW TRIGA Mark-II research reactor has been estimated by using Gaussian plume model $[6,7]$ incorporating the site-specific data available in the methodology sections in this paper.

\section{EXPERIMENTAL}

\section{1. Source Term and Source Term Calculations}

The release of radioactive substances from a research reactor to the environment depends on various factors whereas source term occupies the vital position. The absorbed dose to the members of the public from radionuclide concentrations around a nuclear facility directly depends on source term. The source term calculation plays the central role to calculate the release rate of radioactive substances from a research reactor to the environment. In the present study, the source term calculation has been performed to estimate the radiation received by the members of the public around the TRIGA reactor facility. Based on the calculated release rate of radioactive substances, the concentrations of ${ }^{137} \mathrm{Cs}$ and ${ }^{90} \mathrm{Sr}$ in air along various directions have been estimated. In the present study, doses have been calculated by considering a defined source term taking the following assumptions:

- The reactor is operated at full power which is $3 \mathrm{MW}(\mathrm{t})$ [' $\mathrm{t}$ ' stands for thermal]

- Time after the start up of irradiation: 30 days 
- Duration of continuous operation at full power: 10 days

- Radionuclide released time into the atmosphere from stack: 1 day after accident

- Radionuclides considered: ${ }^{137} \mathrm{Cs}\left(\mathrm{T}_{1 / 2}=30.1\right.$ yrs. $)$ and ${ }^{90} \mathrm{Sr}\left(\mathrm{T}_{1 / 2}=28.6\right.$ yrs. $)$

- Fraction released [8]: $1 \%$ for both radionuclides

- Leakage rate parameter [7]: $\lambda_{1}=1.157 \times 10^{-7} \mathrm{sec}^{-1}$. i.e., $1 \%$ per day

Although different mathematical relations are available to calculate the released activities, we have used the most reliable expression available in the IAEA TECDOC-643 (2) [9] for calculating released activity as the source term.

$$
A_{i}(t)=0.82 \gamma P\left(1-e^{-\lambda_{i} T}\right) \times e^{-\lambda_{i}(t-T)}
$$

where $A_{i}(t)$ is the released activity of an isotope $i$ at time $t$ after the start of irradiation $(t=0)$, $\gamma$ is the fission yield, $P$ is the power (Megawatts) of the reactor, $\lambda$ is the decay constants of the respective isotope, $T$ is the time of irradiation, and 0.82 represents constant factor.

\section{2. Release Rate from the Stack}

The released rate of radionuclides from the stack is determined by the concentrations of the radionuclides present, the growth and decay rates of the radionuclides, fraction released from fuel to building, the geometry of the containment, the leakage rate parameter and overall the source term. The total activity $Q_{i}(\tau)$ of an isotope $i$ released over time $\tau$, can be calculated by using the following equation [6]:

$$
Q_{i}(\tau)=F_{P} F_{B} A_{i}(t) \frac{\lambda_{l}}{\lambda_{l}+\lambda_{r}}\left[1-e^{-\left(\lambda_{l}+\lambda_{r}\right) \tau}\right]
$$

where the symbols $F_{P}$ and $F_{B}$ stands for the fraction released from fuel to building and the fraction remaining airborne and available to be released from the building to the atmosphere, respectively. Considering the same assumptions taken for source term, the total activity and released rate of ${ }^{137} \mathrm{Cs}$ and ${ }^{90} \mathrm{Sr}$ have been calculated by using Eqs.1 and 2, and are presented in Table 1.

Table 1. Calculated activity and release rate of ${ }^{137} \mathrm{Cs}$ and ${ }^{90} \mathrm{Sr}$ for 10 days operation of research reactor at $3 \mathrm{MW}(\mathrm{t})$ power level.

\begin{tabular}{|c|c|c|c|}
\hline Radionuclide & Fission yield & Total activity in core $\mathbf{( k B q )}$ & Release rate $\left(\mathbf{B q} \mathbf{~ s e c}^{\mathbf{- 1}}\right)$ \\
\hline $137 \mathrm{Cs}$ & 0.059 & $3.393 \times 109$ & $3.927 \times 103$ \\
\hline $90 \mathrm{Sr}$ & 0.058 & $3.543 \times 109$ & $4.099 \times 103$ \\
\hline
\end{tabular}

\section{3. Concentration of ${ }^{137} \mathrm{Cs}$ and ${ }^{90} \mathrm{Sr}$ in air along various directions}

Radionuclide concentration in air around the reactor mainly depends on the release rate of the respective radionuclide. Based on the release rate given in Table 1 and using the 
Equation 6 [10], air concentrations of ${ }^{137} \mathrm{Cs}$ and ${ }^{90} \mathrm{Sr}$ have been calculated for 16 cardinal directions with respect to downwind distance up to 2000 meters from the reactor core. Calculated air concentrations of ${ }^{137} \mathrm{Cs}$ and ${ }^{90} \mathrm{Sr}$ radionuclides are shown in Fig. 1(a, b).

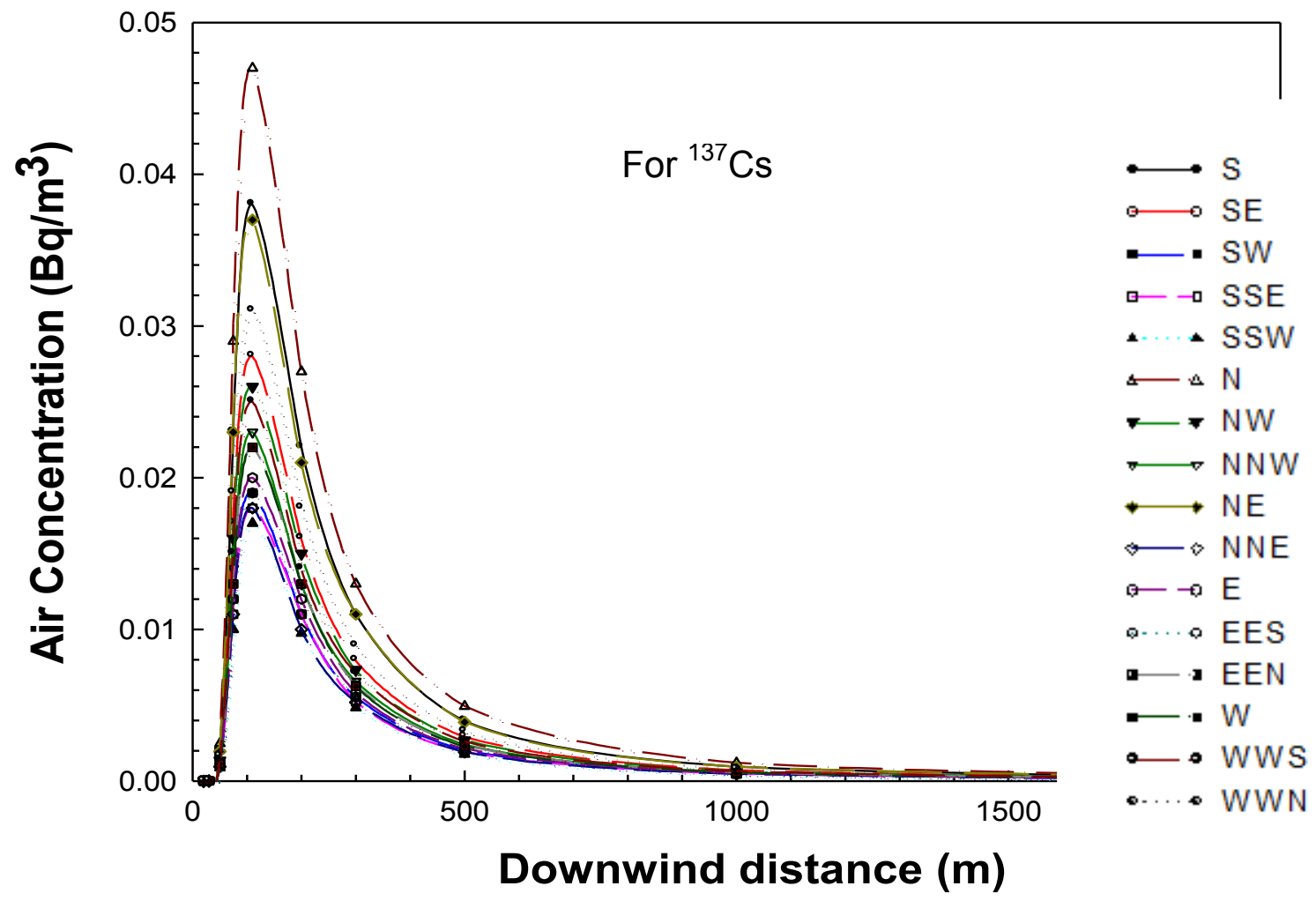

Fig. 1(a). Air concentration of ${ }^{137} \mathrm{Cs}$ at 16 directions as a function of downward distance.

\section{METHOD AND MATERIALS}

The dose calculation methodology for radiological dose assessment around the 3-MW TRIGA Mark II research reactor resulting from a hypothetical accidental release of ${ }^{90} \mathrm{Sr}$ and ${ }^{137} \mathrm{Cs}$ from the reactor has been based on the Gaussian plume model presented in the IAEA safety series $[6,7]$. The most salient features relevant to the dose calculation methodology are given in the following subsections. 


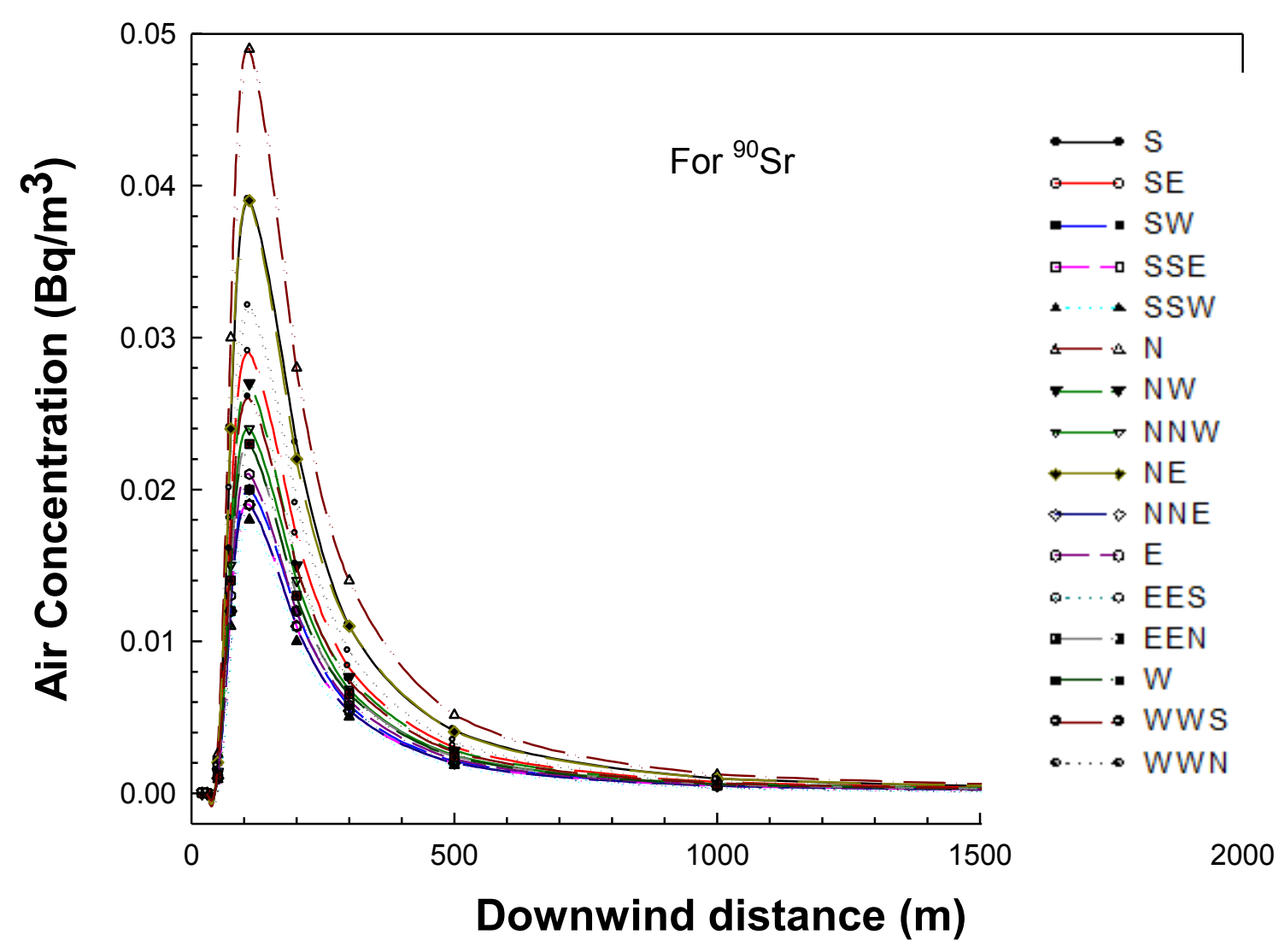

Fig. 1 (b). Air concentration of ${ }^{90} \mathrm{Sr}$ at 16 directions as a function of downward distance.

\section{1. Atmospheric Dispersion}

The estimation of dispersion is commonly approached by the statistical theory of turbulent diffusion or by solving the diffusion equation. The Gaussian plume model is the most widely used method of estimating downwind concentrations of airborne material released to the atmosphere. The dispersion of radioactive materials released into the atmosphere through lateral directions has been estimated by the following equation $[6,7]$ in the present study;

$$
\chi(x, y)=\frac{Q}{2 \pi \cdot \sigma_{y} \cdot \sigma_{z} \cdot u_{a}} \cdot \exp \left(\frac{-y^{2}}{2 \sigma_{y}^{2}}\right)\left\{\exp \left[-\frac{H_{e f f}^{2}}{2 \sigma_{z}^{2}}\right]\right\}
$$

where, $\chi(x, y)$ is the atmospheric concentrations at point $(\mathrm{x}, \mathrm{y})\left(\mathrm{Bq} \mathrm{m}^{-3}\right), \mathrm{Q}$ is the uniform release rate of radioactive materials from the stack $\left(\mathrm{Bq} \mathrm{s}^{-1}\right), u_{a}$ is the wind speed at the effective stack height $\left(\mathrm{m} \mathrm{s}^{-1}\right), \sigma_{\mathrm{y}}$ and $\sigma_{\mathrm{z}}$ are the lateral and vertical dispersion parameters $(\mathrm{m})$, respectively, and $H_{\text {eff }}$ is the effective stack height (m). 


\section{2. Effective stack height and Average wind speed at effective stack height}

The effective stack height [11] has been calculated using the following equation:

$$
H_{e f f}=H+D\left(\frac{v}{u_{a}}\right)^{1.4}\left(1+\frac{\Delta T}{T}\right)
$$

where, $\mathrm{H}$ is the physical height of stack, $\mathrm{D}$ is the outlet stack diameter (m), $v$ is the exit effluent velocity $\left(\mathrm{m} \mathrm{s}^{-1}\right), \Delta \mathrm{T}$ is the difference between ambient and effluent gas temperatures, $\mathrm{T}$ is the absolute temperature of effluent.

Data of wind speed and direction measured at $10 \mathrm{~m}$ height by the meteorological department of Dhaka, Bangladesh have been used in this calculation. For accurate dose calculation, this wind speed has been converted into that of at effective stack height by using the following relation available in the IAEA TECDOC-643 [10];

$$
u_{a}=u_{z}\left(\frac{H_{e f f}}{z}\right)^{m}
$$

where, $u_{z}$ is the speed at ground level at a height $\mathrm{z}=10$ meters and $m$ is the wind coefficient depending on underlying surface and diffusion category.

\section{3. Air concentration of radionuclide and Gaussian diffusion factor}

The sector averaged form of the Gaussian plume model may be used with the following straightforward assumptions: (i) A single wind direction and frequency for each air concentration calculation, (ii) A single long term average wind speed for each direction, and (iii) A neutral atmospheric stability class (i.e., Pasquill-Gifford stability class B [7]). Air concentration [12] of a radionuclide has been calculated based on the above mentioned assumptions using the following equation:

$$
C_{A}=\frac{P_{P} \cdot F \cdot Q_{i}}{u_{a}} \exp \left(-\lambda_{i} \frac{x}{u_{a}}\right)
$$

where, $P_{p}$ is the fraction of the time during the year that the wind blows towards the receptor of interest in sector $\mathrm{p}, Q_{i}$ is the average annual discharge rate for radionuclide $i\left(\mathrm{~Bq} \mathrm{~s}^{-1}\right), \lambda_{i}$ is the decay constant of the respective radionuclide, and $F$ is the Gaussian diffusion factor which has been calculated as a function of downwind distance $\mathrm{x}$ and for a fixed velocity at $H_{\text {eff }}$ using the following equation [8]: 


$$
F=\frac{16}{\sqrt{2 \pi^{3}}} \times \frac{\exp \left[-\left(\frac{H_{e f f}{ }^{2}}{2 \sigma_{z}^{2}}\right)\right]}{x \sigma_{z}}
$$

\section{4. Ground Deposition and Ground Concentration}

The rate at which radioactive material is deposited from the plume will depend on the nature of the airborne material and the underlying surface and can be estimated by using the concept of a deposition velocity specifically, deposition coefficient. The following simplified form of equation has been used to calculate total daily average deposition rate [7] on the ground.

$$
d_{i}=\left(V_{d}+V_{W}\right) C_{A}
$$

where, $d_{i}$ is the total daily average deposition rate on the ground of a given radionuclide $i$ from both dry and wet processes $\left(\mathrm{Bq} \mathrm{m}^{-2} \mathrm{~d}^{-1}\right), V_{d}$ is the dry deposition coefficient for a given radionuclide $\left(\mathrm{m} \mathrm{d}^{-1}\right), V_{w}$ is the wet deposition coefficient for a given radionuclide $\left(\mathrm{m} \mathrm{d}^{-1}\right)$, and $C_{A}$ is the radionuclide concentration in $\operatorname{air}\left(\mathrm{Bq} \mathrm{m}^{-3}\right)$.

Once the value of ground deposition $d_{i}$ is obtained, the ground concentration $C_{g r}$ has been calculated by using the following relation [7];

$$
C_{g r}=\frac{d_{i}\left[1-\exp \left(-\lambda_{E_{i}^{s}} \cdot t_{b}\right)\right]}{\lambda_{E_{i}^{s}}}
$$

where, $\lambda_{E_{i}^{S}}$ is the effective rate constant for reduction of the activity concentration in the root zone of soil $\left(\mathrm{d}^{-1}\right)$, and $t_{b}$ is the duration of the discharge of radioactive material (assumed 1day).

\section{5. Concentrations in Vegetation}

Radionuclides intercepted by and retained on vegetation may result from fallout, washout, rainout and irrigation with contaminated water or deposition of resuspended matter. External deposits can be taken up by foliar absorption into plants. Radionuclides may also be incorporated by uptake from the soil through roots. The total concentration $C_{v, i}$ of the $i^{\text {th }}$ radionuclide in the vegetation at the time of consumption has been calculated by the next equation [7]:

$$
C_{v, i}=\left(C_{v, i, 1}+C_{v, i, 2}\right) \exp \left(-\lambda_{i} t_{h}\right)
$$


where, $C_{v, i, 1}$ is the concentration of radionuclide $i$ in and on vegetation due to direct contamination, $C_{v, i, 2}$ is the radionuclide concentration in vegetable arising from indirect uptake processes from the soil and from soil adhering to the vegetation, and $t_{h}$ is the decay (hold-up) time that represents the time interval between harvest and consumption of the food which is equal to $14 \mathrm{~d}$ [8].

\section{6. Concentrations in Animal Feed}

The concentration of radionuclide $i$ in animal feed $C_{a, i}$ has been calculated by using the following equation [7]:

$$
C_{a, i}=f_{p} \cdot C_{v, i}+\left(l-f_{p}\right) \cdot C_{p, i}
$$

where, $C_{v, i}$ is the concentration of radionuclide $i$ for pasture, with $t_{h}=0, C_{p, i}$ is the concentration of radionuclide in stored feeds and substituting $C_{p, i}$ for $C_{v, i}$ with $t_{h}=90$ days, and $f_{p}$ is the fraction of the year that animals consume fresh pasture vegetation which is 0.7 [8].

\section{7. Concentration in Milk and Meat}

The concentration of a radionuclide in milk depends directly on the radioactivity concentration of the feed consumed by the lactating animal. The concentration of $i^{\text {th }}$ radionuclide in milk $C_{m, i}$ [7] has been estimated by using the following equation:

$$
C_{m, i}=F_{m i l k}\left(C_{a, i} Q_{m}+C_{w, i} Q_{w}\right) \exp \left(-\lambda_{i} t_{m}\right)
$$

where, $C_{\alpha, i}$ is the concentration of radionuclide $i$ in the animal feed, $C_{w, i}$ is the concentration of radionuclide $i$ in water $\left(\mathrm{Bq} \mathrm{m}^{-3}\right) ; F_{\text {milk }}$ is the fraction of the animal's daily intake of the radionuclide that each liter of milk at equilibrium which is 0.003 for ${ }^{90} \mathrm{Sr}$ and and $0.01 \mathrm{~d} \mathrm{~L}^{-1}$ for ${ }^{137} \mathrm{Cs}$ [8], $Q_{m}$ is the amount of feed (in dry matter) consumed by the animal per day which is $16 \mathrm{~kg} \mathrm{~d}^{-1}$ (dry weight) [9], $Q_{w}$ is the amount of water consumed by the animal per day which is $0.06 \mathrm{~m}^{3} \mathrm{~d}^{-1}$ [8], and $t_{m}$ is the average time between collection and human consumption.

On the other hand, radionuclide concentration in meat depends directly on the amount and contamination level of the feed consumed by the animal. The concentration of $i^{\text {th }}$ radionuclide in meat, $C_{f, i}$ [7] has been calculated using similar fashion of milk concentration calculations;

$$
C_{f, i}=F_{\text {meat }}\left(C_{a, i} Q_{m}+C_{w, i} Q_{W}\right) \exp \left(-\lambda_{i} t_{f}\right)
$$

\section{8. External Doses from Immersion}

The annual effective dose [7] from immersion in the atmospheric discharge plume, $E_{i m}$ has been estimated by 


$$
E_{\text {im }}=C_{A} \cdot D F_{i m} \cdot Q_{f}
$$

where, $C_{A}$ is the annual average concentration of nuclide $i$ in air $\left(\mathrm{Bq} \mathrm{m}^{-3}\right), D F_{\text {im }}$ is the effective dose coefficient for immersion $\left(\mathrm{Sv} \mathrm{yr}^{-1}\right.$ per $\left.\mathrm{Bq} \mathrm{m}^{-3}\right)$, and $Q_{f}$ is the fraction of the year for which the hypothetical critical group member is exposed to this particular pathway.

\section{9. Internal Doses from Inhalation}

The internal dose following an intake of radioactive material into the body by inhalation is prolonged in time after the intake.

The annual effective dose [7] from inhalation of airborne radionuclide, $E_{i n h}$ has been calculated by using the equation given below;

$$
E_{i n h}=C_{A} \cdot R_{i n h} \cdot D F_{i n h}
$$

where, $C_{A}$ is the radionuclide concentration in air $\left(\mathrm{Bq} \mathrm{m}^{-3}\right), R_{\text {inh }}$ is the inhalation rate $\left(\mathrm{m}^{3} \mathrm{yr}^{-}\right.$ $\left.{ }^{1}\right)$, and $D F_{i n h}$ is the inhalation dose coefficient $\left(\mathrm{Sv} \mathrm{Bq}^{-1}\right)$.

\section{10. External Doses from Ground Deposition}

The annual effective external dose [8] from ground deposition, $\mathrm{E}_{\mathrm{gr}}$ has been estimated by using the subsequent equation:

$$
E_{g r}=C_{g r} \cdot D F_{g r} \cdot Q_{f}
$$

where, $D F_{g r}$ is the coefficient for exposure to ground depositions $\left(\mathrm{Sv} \mathrm{yr}^{-1}\right.$ per $\left.\mathrm{Bq} \mathrm{m}^{-3}\right) ; Q_{f}$ is the fraction of the year which the hypothetical critical group member is expressed to this particular pathways.

\section{11. Internal Dose from Food Ingestion}

The internal dose from food ingestion to human (adults) [7] has been calculated by using the general equation next;

$$
E_{\text {ing,p }}=C_{p, i} \cdot H_{p} \cdot D F_{\text {ing }}
$$

where, $E_{\text {ing, } p}$ is the annual effective dose from consumption of nuclide $\mathrm{i}$ in foodstuff $\mathrm{p}$ ( $\mathrm{Sv} \mathrm{\textrm {yr } ^ { - }}$ $\left.{ }^{1}\right), C_{p, i}$ is the concentration of radionuclide $\mathrm{i}$ in foodstuff $\mathrm{p}$ at the time of consumption $\left(\mathrm{Bq} \mathrm{kg}^{-}\right.$ $\left.{ }^{1}\right), \mathrm{H}_{\mathrm{p}}$ is the consumption rate for foodstuff $\mathrm{p}\left(\mathrm{kg} \mathrm{yr}^{-1}\right), D F_{\text {ing }}$ is the dose coefficient for ingestion of radionuclide $\mathrm{i}\left(\mathrm{Sv} \mathrm{Bq}{ }^{-1}\right)$.

The internal dose resulting from ingestion of vegetation $\left(E_{\text {ing, },}\right)$, milk $\left(M_{\text {ing, } m}\right)$ and meat $\left(E_{\text {ing,meat }}\right)$ have been calculated by using the Eqn.17, with replacing the radionuclide concentration $C_{p, i}$, by the respective concentrations of the abovementioned media, i.e., $C_{v, i}$, $C_{m, i}$ and $C_{m e a t, i}$, for vegetable, milk and meat, respectively. 


\section{12. Total Dose}

The total effective dose to the members of the critical group for individual radionuclide, $E_{\text {total }}$ [7] has been obtained by adding the doses of all possible pathways such as ingestion dose (i.e. from vegetables, milk and meat), inhalation dose and external dose from immersion and ground deposition as

$$
E_{\text {total }}=E_{\text {im }}+E_{\text {inh }}+E_{g r}+E_{\text {ing,v }}+E_{\text {ing, } m}+E_{\text {ing, meat }}
$$

where, $E_{i m}$ is the external dose from immersion, $E_{i n h}$ is the internal dose from inhalation, $E_{g r}$ is the external dose from ground deposition, $E_{i n g, v}$ is the internal dose from ingestion of vegetation, $E_{\text {ing, } m}$ is the internal dose from ingestion of milk, and $E_{\text {ing,meat }}$ is the internal dose from ingestion of meat.

A computational code has been developed using Mathcad software based on the abovementioned mathematical expressions to calculate the concentrations and doses for various pathways. It is noted that the developed code is useful to calculate the dose to the members of the public due to the immersion, inhalation, and ingestion of vegetable, milk and meat.

\section{RESULTS AND DISCUSSION}

Radiological dose due to the release of radionuclides ${ }^{137} \mathrm{Cs}$ and ${ }^{90} \mathrm{Sr}$ via the stack of a 3 MW TRIGA MARK-II research reactor has been estimated from ground deposition, immersion, internal dose due to inhaled airborne radionuclide and ingestion of vegetables, milk and meat. Furthermore, relations between air concentration of each radionuclide and total effective dose rate in different pathways have also been developed. The results of the measurements along with the discussion are given in the following segments.

It is obvious from the breakthrough of Fig. 1 that maximum air concentrations along all the directions were found at $110 \mathrm{~m}$ distance from the core of the reactor for both the radionuclides and decreased exponentially from peak concentration following the dispersion equation of Gaussian plume model. The highest air concentration was found in the northern direction.

\section{1. Total effective dose around the research reactor}

Considering the air concentration of ${ }^{137} \mathrm{Cs}$ and ${ }^{90} \mathrm{Sr}$ along with the downwind distance from the reactor core, total effective dose rates for various pathways (i.e., immersion, inhalation and ingestion of food) in all the directions have been calculated which has are shown in Figs. 2-3. From the figures it is clear that dose rate has been the maximum at $110 \mathrm{~m}$ distance for all directions and after that it decreases rapidly but totally disappeared with a distance of $1000 \mathrm{~m}$ or more. The maximum dose rates in 16 cardinal directions are given in Table 2. The highest dose rates have been found in N-direction which are 0.014, 0.036 and $0.050 \mu \mathrm{Sv} \mathrm{hr}{ }^{-1}$ for ${ }^{137} \mathrm{Cs},{ }^{90} \mathrm{Sr}$ and for both ${ }^{137} \mathrm{Cs}$ and ${ }^{90} \mathrm{Sr}$, respectively. On the other hand, the lowest dose rates have been found in SSW direction. The total effective dose rates in various pathways for both ${ }^{137} \mathrm{Cs}$ and ${ }^{90} \mathrm{Sr}$ and for all the directions lies in the range of $0.02 \mu \mathrm{Sv} \mathrm{hr}{ }^{-1}$ to $0.05 \mu \mathrm{Sv} \mathrm{hr} r^{-1}$. These values are much lower than the IAEA tolerable dose rate limit for the members of public which is $0.5 \mu \mathrm{Sv} \mathrm{hr}^{-1}$ [12]. 
Table 2. Maximum total effective dose rate in all 16 directions (immediately after the accident).

\begin{tabular}{|c|c|c|c|}
\hline \multirow{2}{*}{ Direction } & \multicolumn{3}{|c|}{ Total dose rate $\left(\mu \mathrm{Sv} \mathrm{hr}^{-1}\right)$} \\
\hline & ${ }^{137} \mathrm{Cs}$ & ${ }^{90} \mathrm{Sr}$ & ${ }^{137} \mathrm{Cs}$ and ${ }^{90} \mathrm{Sr}$ \\
\hline North (N) & 0.014 & 0.036 & 0.050 \\
\hline South (S) & 0.011 & 0.029 & 0.040 \\
\hline (North-East)NE & 0.011 & 0.028 & 0.039 \\
\hline West-West-North (WWN) & $9.03 \times 10^{-3}$ & 0.024 & 0.033 \\
\hline South-East (SE) & $8.05 \times 10^{-3}$ & 0.021 & 0.029 \\
\hline North-West (NW) & $7.42 \times 10^{-3}$ & 0.019 & 0.027 \\
\hline West-West-South (WWS) & $7.20 \times 10^{-3}$ & 0.019 & 0.026 \\
\hline North-North-West (NNW) & $6.65 \times 10^{-3}$ & 0.017 & 0.024 \\
\hline East-East-North (EEN) & $6.42 \times 10^{-3}$ & 0.017 & 0.023 \\
\hline West (W) & $6.32 \times 10^{-3}$ & 0.017 & 0.023 \\
\hline South-West (SW) & $5.61 \times 10^{-3}$ & 0.015 & 0.020 \\
\hline East (E) & $5.90 \times 10^{-3}$ & 0.015 & 0.021 \\
\hline East-East-South (EES) & $5.63 \times 10^{-3}$ & 0.015 & 0.020 \\
\hline South-South-East (SSE) & $5.18 \times 10^{-3}$ & 0.014 & 0.019 \\
\hline North-North-East (NNE) & $5.27 \times 10^{-3}$ & 0.014 & 0.019 \\
\hline South-South-West (SSW) & $4.90 \times 10^{-3}$ & 0.013 & 0.018 \\
\hline
\end{tabular}

\section{2. Relation between air concentration and total dose rate for various pathways}

It is important to know the relationship between air concentration and total dose rate for different pathways. Air concentration of ${ }^{137} \mathrm{Cs}$ and ${ }^{90} \mathrm{Sr}$ for each direction with varying downwind distance and corresponding total effective dose rates for various pathways for all directions have been calculated. Finally total dose and air concentration are plotted and presented in Figures 2-3. 

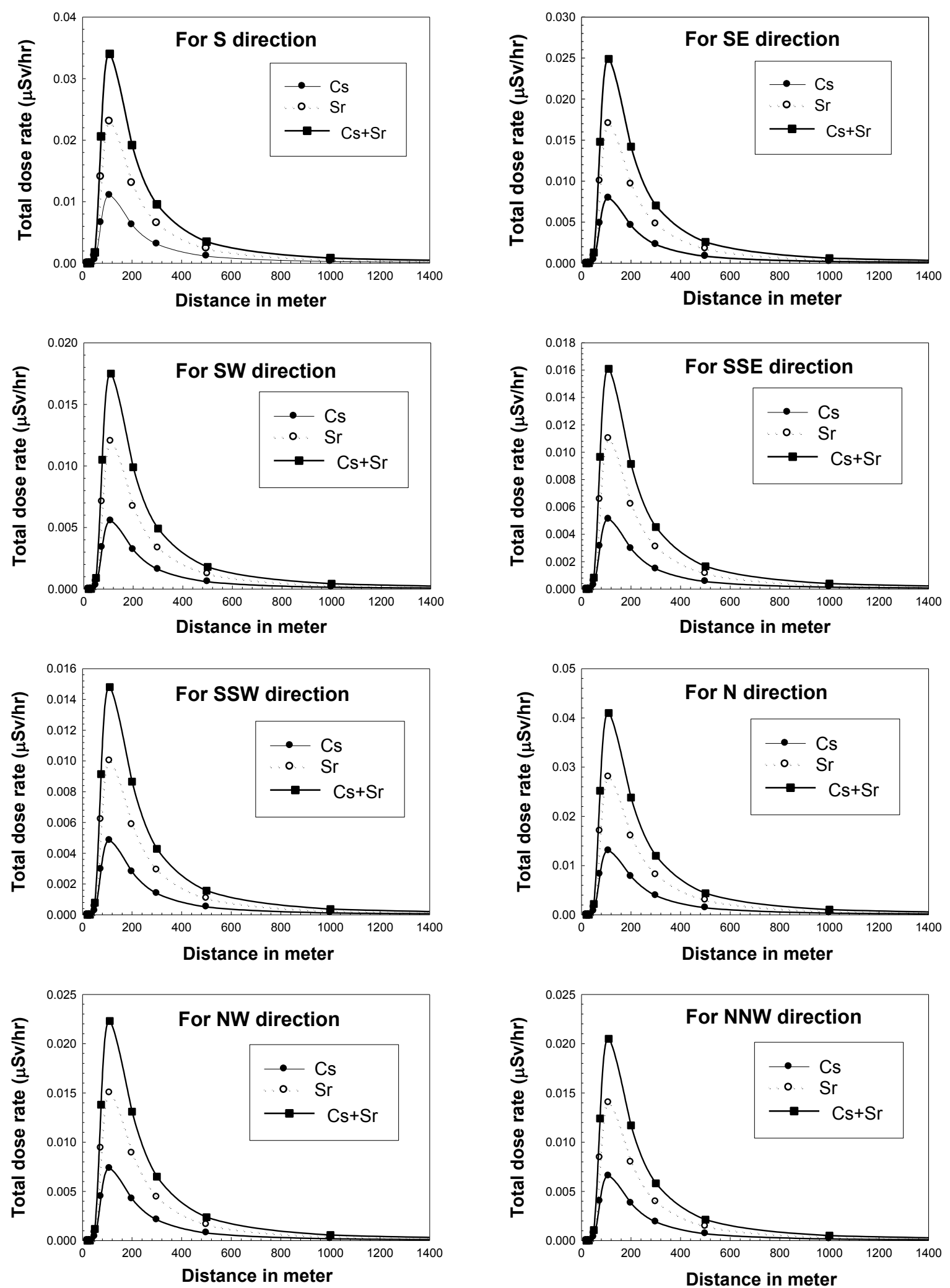

Fig. 2. Total dose rate at various pathways as a function of downwind distance (m) for directions S, SE, SW, SSE, SSW, N, NW and NNW. 

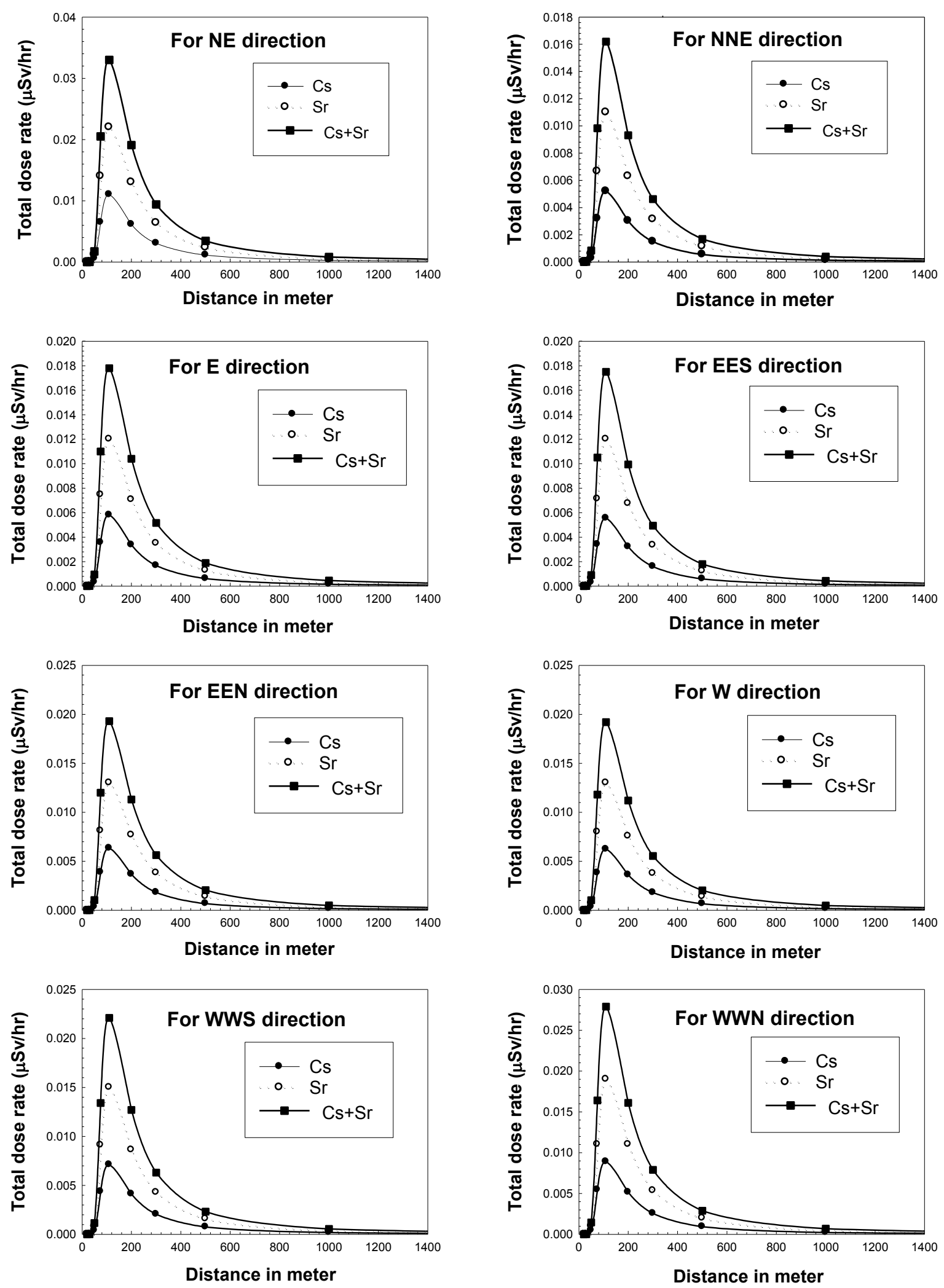

Fig. 3. Total dose rate at various pathways as a function of downwind distance (m) for directions NE, NNE, E, EES, EEN, W, WWS and WWN. 
From Figs. 4 and 5 it is clear that the total dose rates in various pathways are directly proportional to the air concentration. The relations between total dose rate and air concentration in different directions for ${ }^{137} \mathrm{Cs}$ and ${ }^{90} \mathrm{Sr}$ are given in Table 3.

Table 3. Relationship for total dose at various pathways and air concentration.

\begin{tabular}{|c|c|c|}
\hline Direction & Relation for 137Cs & \multicolumn{1}{c|}{ Relation for 90Sr } \\
\hline S & Total Dose $=0.584 \times$ Air Concentration & Total Dose $=0.288 \times$ Air Concentration \\
\hline SE & Total Dose $=0.581 \times$ Air Concentration & Total Dose $=0.284 \times$ Air Concentration \\
\hline SW & Total Dose $=0.588 \times$ Air Concentration & Total Dose $=0.290 \times$ Air Concentration \\
\hline SSE & Total Dose $=0.568 \times$ Air Concentration & Total Dose $=0.280 \times$ Air Concentration \\
\hline SSW & Total Dose $=0.563 \times$ Air Concentration & Total Dose $=0.286 \times$ Air Concentration \\
\hline N & Total Dose $=0.571 \times$ Air Concentration & Total Dose $=0.281 \times$ Air Concentration \\
\hline NW & Total Dose $=0.569 \times$ Air Concentration & Total Dose $=0.281 \times$ Air Concentration \\
\hline NNW & Total Dose $=0.575 \times$ Air Concentration & Total Dose $=0.286 \times$ Air Concentration \\
\hline NE & Total Dose $=0.574 \times$ Air Concentration & Total Dose $=0.292 \times$ Air Concentration \\
\hline NNE & Total Dose $=0.572 \times$ Air Concentration & Total Dose $=0.291 \times$ Air Concentration \\
\hline E & Total Dose $=0.575 \times$ Air Concentration & Total Dose $=0.289 \times$ Air Concentration \\
\hline EES & Total Dose $=0.589 \times$ Air Concentration & Total Dose $=0.289 \times$ Air Concentration \\
\hline EEN & Total Dose $=0.572 \times$ Air Concentration & Total Dose $=0.288 \times$ Air Concentration \\
\hline W & Total Dose $=0.569 \times$ Air Concentration & Total Dose $=0.283 \times$ Air Concentration \\
\hline WWS & Total Dose $=0.575 \times$ Air Concentration & Total Dose $=0.287 \times$ Air Concentration \\
\hline WWN & Total Dose $=0.581 \times$ Air Concentration & Total Dose $=0.287 \times$ Air Concentration \\
\hline
\end{tabular}

The Table 3 indicates that the value of constant of proportionality for ${ }^{137} \mathrm{Cs}$ in all the directions are nearly equal and for ${ }^{90} \mathrm{Sr}$ are also separately equal. Thus the general relation between the total effective dose rates for various pathways and air concentration for ${ }^{137} \mathrm{Cs}$ and ${ }^{90} \mathrm{Sr}$ can be written as:

Total EffectiveDose Rate $=0.575 \times$ Air Concentration for ${ }^{137} \mathrm{Cs}$

Total EffectiveDose Rate $=0.286 \times$ Air Concentration for ${ }^{90} \mathrm{Sr}$

These general equations $(19-20)$ could be applied for the calculation of total effective dose rate $\left(\mu \mathrm{Sv} \mathrm{hr}{ }^{-1}\right)$ at various pathways from air concentration $\left(\mathrm{Bq} \mathrm{m}{ }^{-3}\right)$ around the reactor facility. 

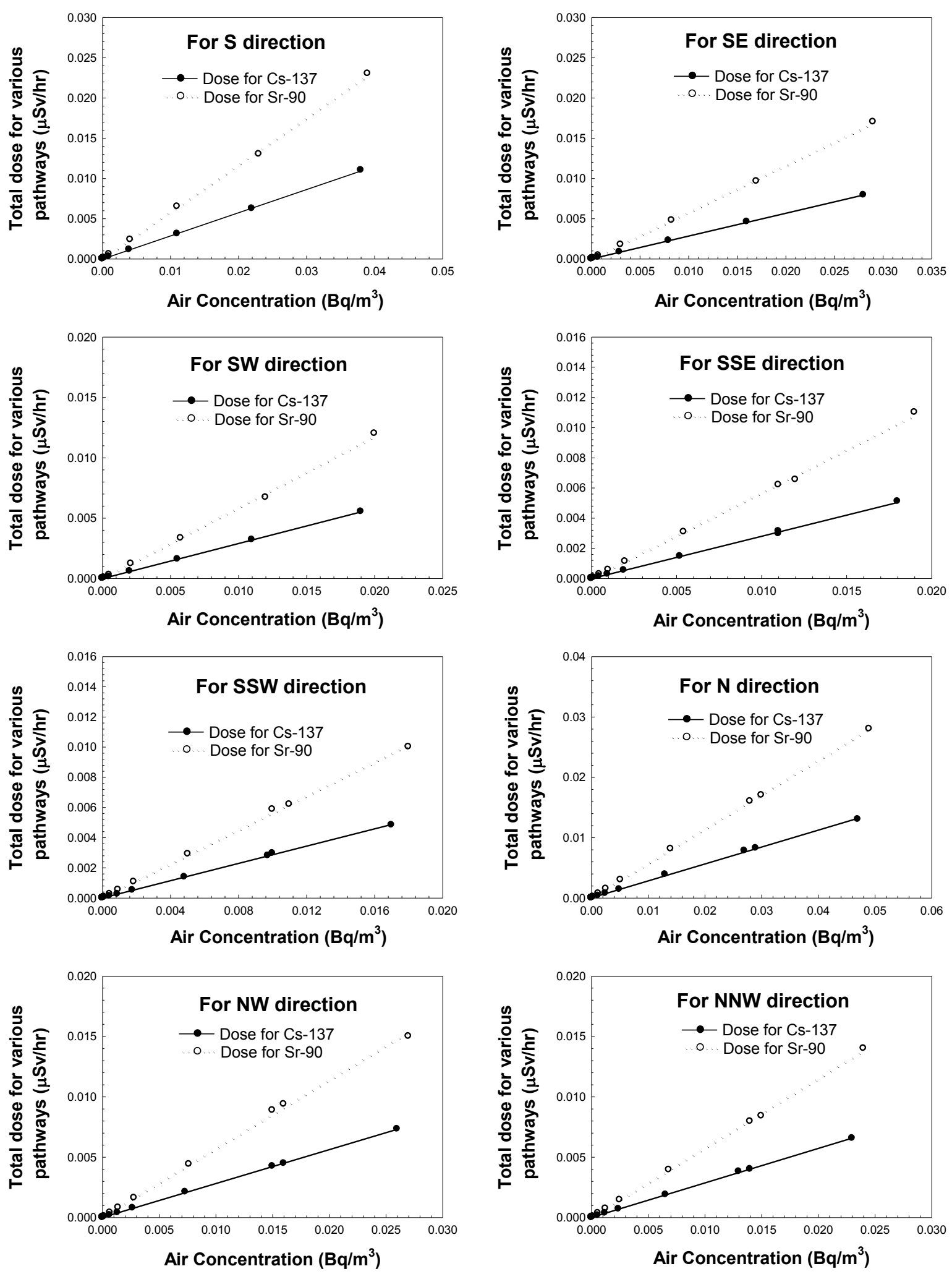

Fig. 4. Total dose rate at various pathways as a function of air concentration $\left(\mathrm{Bq} / \mathrm{m}^{3}\right)$ for directions $\mathrm{S}$, SE, SW, SSE, SSW, N, NW and NNW. 

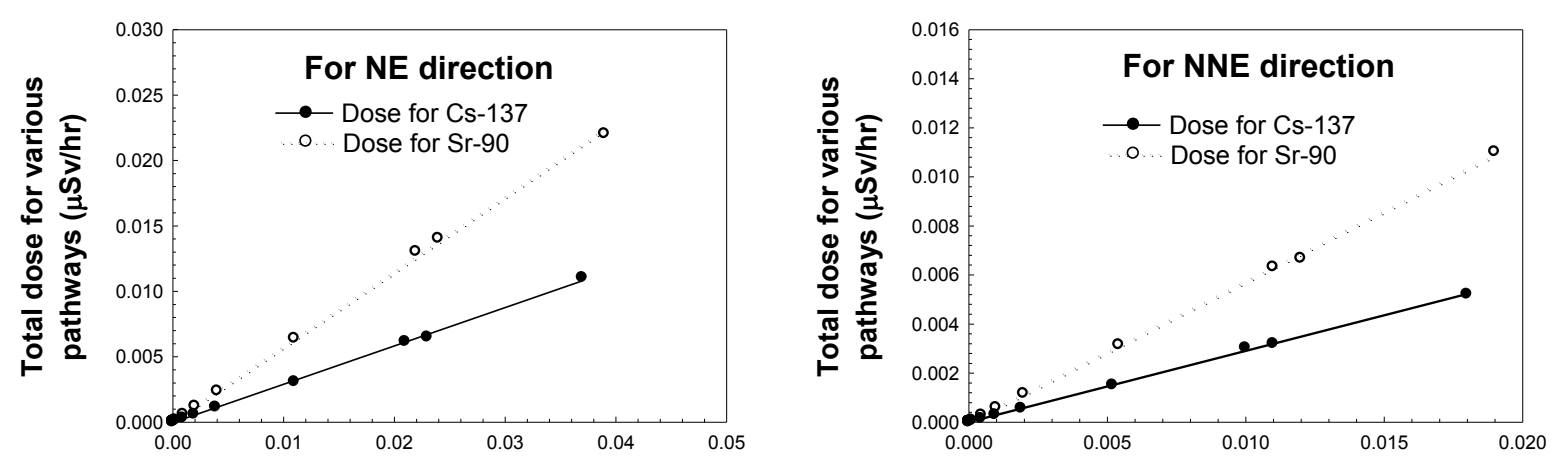

Air Concentration $\left(\mathrm{Bq} / \mathrm{m}^{3}\right)$
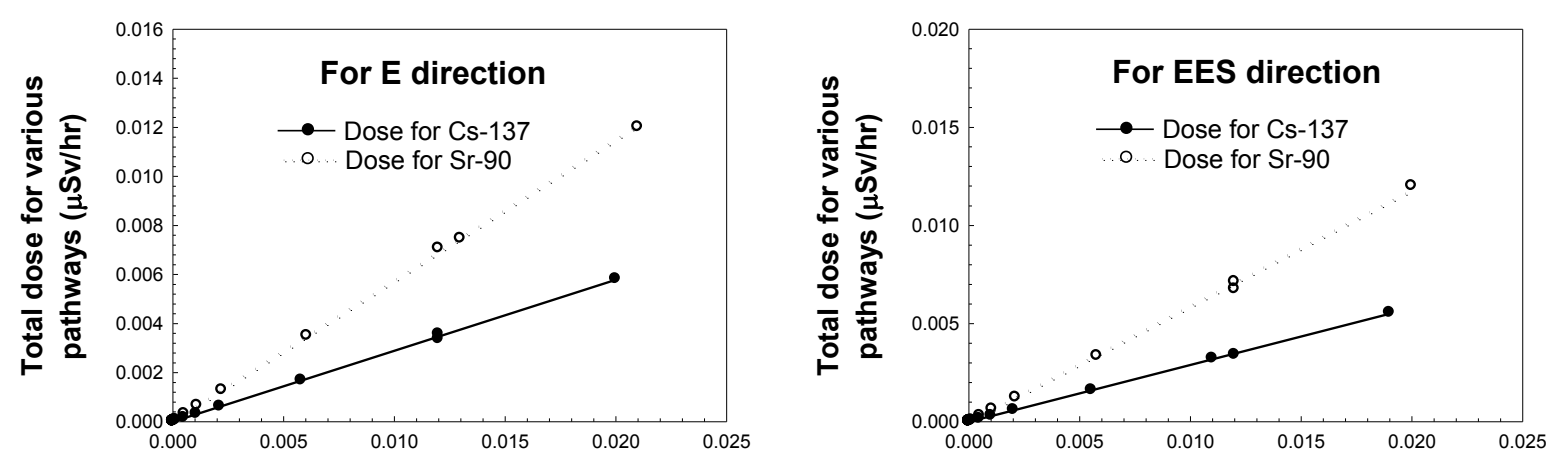

Air Concentration $\left(\mathrm{Bq} / \mathrm{m}^{3}\right)$
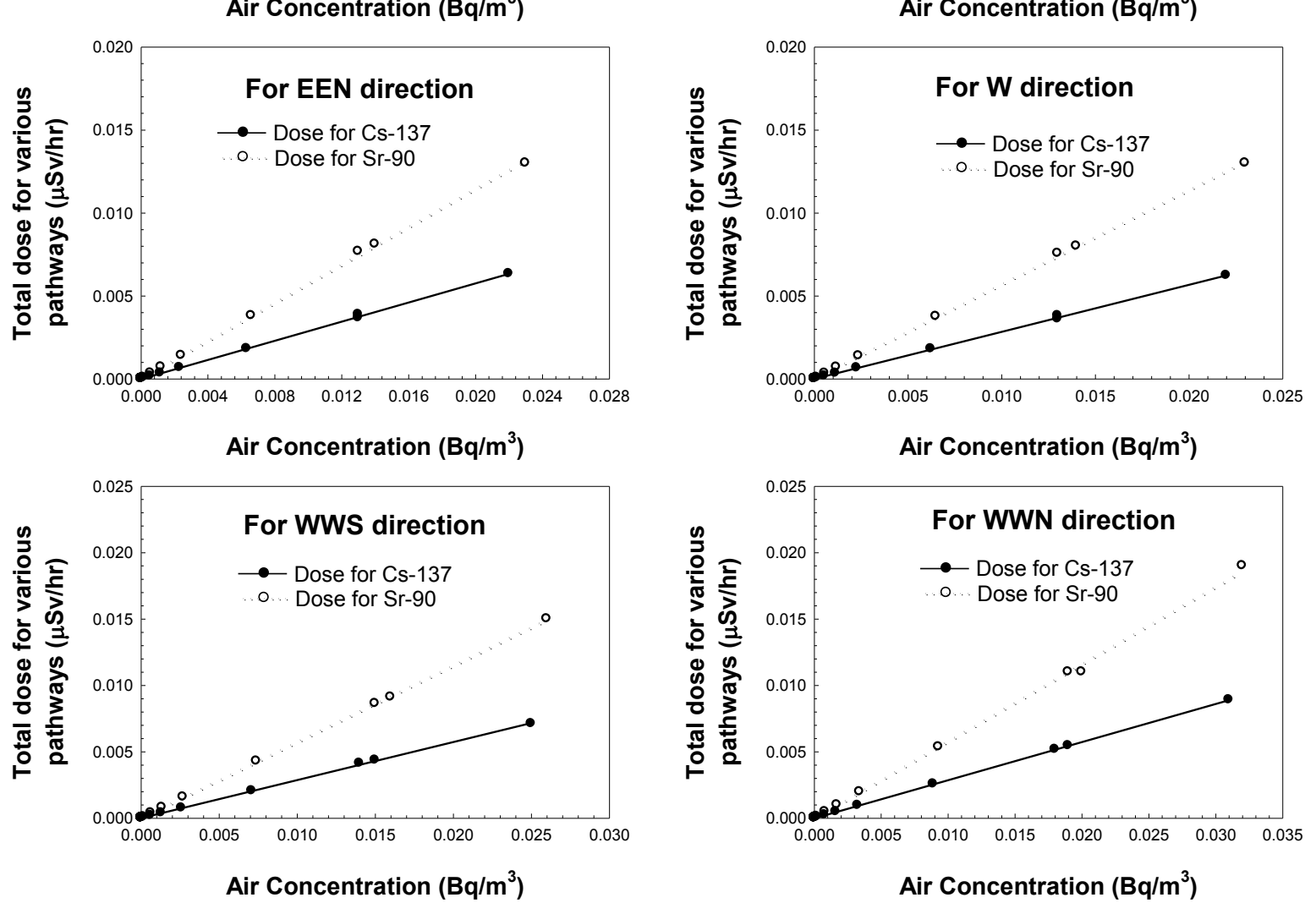

Fig. 5. Total dose rate at various pathways as a function of air concentration $\left(\mathrm{Bq} / \mathrm{m}^{3}\right)$ for directions NE, NNE, E, EES, EEN, W, WWS and WWN. 


\section{CONCLUSIONS}

The radiological effects due to release of radionuclides for a hypothetical accident of a TRIGA Mark-II research reactor has been evaluated based on the atmospheric dispersion phenomena of radionuclides. The different parameters such as, effective stack height, dispersion factor, wind speed, wind frequency and stability class have been investigated prior to the assessment of dose in various pathways.

The air concentrations for ${ }^{137} \mathrm{Cs}$ and ${ }^{90} \mathrm{Sr}$ radionuclides in sixteen cardinal directions have been estimated. Air concentrations and effective dose rate to the members of the public have been estimated through various pathways like ingestion from vegetation, milk and meat as well as from ground deposition. A relationship between them has been established to estimate the dose to the human via various pathways as a function of air concentration of accumulated radionuclides. The total dose is found to be directly proportional to the air concentration of ${ }^{137} \mathrm{Cs}$ and ${ }^{90} \mathrm{Sr}$ radionuclides. The breakthrough results for various hypothetical accidental conditions indicate that the estimated total and individual dose rates of ${ }^{137} \mathrm{Cs}$ and ${ }^{90} \mathrm{Sr}$ for the members of the public are lower than the IAEA acceptable dose limit. The result of this study might provide information on the radiological safety required for the radiation protection purposes in the atmospheric environment around the research reactor TRIGA Mark-II.

\section{References}

[1] Merril Eisenbud, Environmental Radioactivity, Chap. 5, pp. 118-136, Academic Press, New York, 1973.

[2] Rosalie Berlell, No Immediate Danger: Prognosis for a Radioactive Earth, (ISBN 0-913990-25-2), 2000, pages 15-63.

[3] D. McCurdy, L-Q. Tai, S. Frias, Z. Wang, Radiation Research 147(1) (1997) 48-54.

[4] Z. S. Beauvais, K. H. Thompson, K. J. Kearfott, Health Physics 97(1) (2009) 50-67.

[5] International Atomic Energy Agency, Generic Procedures for Assessment and Response during a Radiological Emergency, IAEA-TECDOC-1162, IAEA, Vienna, (2000).

[6] International Atomic Energy Agency, Generic Models and Parameters for Assessing the Environmental Transfer of Radionuclides from Routine Releases, SRS No. 57, 1982.

[7] International Atomic Energy Agency, Generic Models for Use in Assessing the Impact of Discharges of Radioactive Substances to the Environment, Safety Series No. 19, IAEA, Vienna 2001.

[8] W. L. Woodruff, D. K. Warinner, J. E. Matos, Radiological Consequence Analysis, Research Reactor Core Conversion Guidebook, IAEA-TECDOC- 643, Vol. 2, pp. 155-178, IAEA, Vienna, 1992.

[9] J. N. Anoussis, N. G. Chrysochoides, Estimation of Radiological Doses from Research Reactor Accidents, International Atomic Energy Agency, Research Reactor Core Conversion Guidebook, IAEA TECDOC- 643, Vol. 2, pp. 185-200, IAEA, Vienna,1992.

[10] INTERATOM, Bergisch Gladbach, Federal Republic of Germany; Fundamental Calculation Model for the Determination of the Radiological Effects, Inside and 
Outside A Research Reactor, After Hypothetical Accidents, With Release of High Amount of Fission Products From the Core; Research Reactor Core Conversion Guidebook, IAEA-TECDOC-643, Vol. 2, pp. 211 - 232, IAEA, Vienna, (1992).

[11] Herman Cember, Thomas E. Johnson, Introduction to Health Physics, Fourth Edition, page no. 609, The McGraw-Hill Companies Inc., 2009.

[12] International Basic Safety Standards for Protection against Ionizing Radiation and for the Safety of Radiation Sources, Safety Series No. 115, IAEA, Vienna (1996). 